\title{
Experimental resection of the intestine in newborn pigs
}

\author{
By R. A. McCANCE* \\ Medical Research Council Department of Experimental Medicine, \\ University of Cambridge \\ AND A. W. WILKINSON \\ Institute of Child Health and The Hospital for Sick Children, Great \\ Ormond Street, London
}

(Received 27 January 1967-Accepted 21 April 1967)

\begin{abstract}
I. The whole of the lower half of the small intestine, with the exception of the last few $\mathrm{cm}$ of the ileum, has been removed from sixteen suckling pigs, $3-4 \mathrm{~kg}$ in weight.

2. The operation is technically easy, but the exposure and handling of the intestines may produce crippling adhesions.

3. The postoperative management presents no serious nutritional difficulties.

4. If the operation is successful the animals become functionally normal, if slightly small, adults.
\end{abstract}

It is occasionally necessary to resect a large portion of the small intestine in newborn children, most commonly because of gangrene following a volvulus. In some children the total length of the small intestine may have been reduced by atresia, probably the result of an intra-uterine infarction, and the operative treatment inevitably produces a further reduction in its total length. Great diminution in length of the small intestine may prevent the baby from obtaining sufficient nutrients from its food to provide for both growth and maintenance, but infants may develop reasonably well after the removal of very large portions of the small intestine (Pilling \& Cresson, I957).

The effects of the removal of large segments of the small intestine depend on the amount and location of the parts that remain. It is generally agreed that it is highly desirable to leave the ileocaecal valve intact (Pietz, I956) and enough of the lowest segment of the ileum to prevent a deficiency of vitamin $B_{12}$ (Clark \& Booth, 1960 ; Booth \& Mollin, I959). Although it is difficult to measure how much of the small intestine remains after such operations, it seems likely that at least Io-r $5 \%$ of it $(35-40 \mathrm{~cm}$ ) are necessary for survival (Wilkinson, Hughes \& Toms, I963). Flint (I9 I 2 ) found that $50 \%$ of the small intestine could be removed from adult dogs with survival for long periods, and that the operation was followed by hypertrophy and hyperplasia of the remaining portions of the intestine. Althausen, Doig, Uyeyama \& Weiden ( $95^{\circ}$ ) also suggested that there may be compensatory hypertrophy, elongation and dilatation of the residual portions of intestine. Clatworthy, Saleeby \& Lovingood (1952) resected from 40 to $80 \%$ of the small intestine of nineteen young dogs weighing $0.5-$ $2 \mathrm{~kg}$, of whom seven survived more than I5 weeks. The remainder of the small

* Present address: Infantile Malnutrition Research Unit, Kampala, Uganda. 
intestine increased in diameter and thickness, but not in length. Dilatation varied with the extent of the resection. Growth was not seriously impaired in most of these animals, but the animal shown as the control in their Fig. 2 was evidently destined to become a smaller adult. Booth, Evans, Menzies \& Street (1959) used adult rats and found that after resections of the lower half of the small intestine the transit time for a barium meal became more rapid, but that the hypertrophy of the proximal half was negligible, whereas, after resection of the upper half, the transit time remained normal, but there was great hypertrophy of the lower half. This seems a logical finding if the dilatation and enlargement are the result of a 'work hypertrophy' (Jervis \& Levin, I.966), for it is difficult to see why removal of the distal half of the intestine should throw any more work on to the upper half, as all the food and secretions must pass through it anyway, whatever their fate lower down. To obtain further information about the effects of extensive resection of the intestine, we have selected the newborn pig as the experimental subject, because its weight resembles that of the human neonate while its rate of growth is very much more rapid. It was planned in particular to study (I) the possibilities of carrying out such an operation, (2) the nature and extent of the subsequent hypertrophy, (3) the nutritional sequelae, (4) the ultimate result.

\section{EXPERIMENTAL}

Animals. Sixteen pigs have been operated upon, usually when they were IO-I 4 days old, and weighed between 3.2 and $4.0 \mathrm{~kg}$. The small intestine of eight other pigs of similar age and weight varied in length, after death, from $5^{64}$ to $860 \mathrm{~cm}$, and the average was $760 \mathrm{~cm}$. Most animals to be operated upon were taken direct from the sow and fed after the operation on Amvilac no. I (Glaxo Laboratories Ltd), but some were partially weaned on to Amvilac before operation.

Intestinal anatomy. A preliminary survey of the anatomy of the small intestine of the pig showed that it was satisfactory for the purpose in hand. The blood supply is provided mainly by three arteries. One enters the mesentery near the upper end and runs distally close to the intestine accompanied by a large venous channel. Another artery enters the mesentery of the small intestine about the middle, and close to the bowel it divides into two main stems; one of these runs proximally to anastomose with the upper artery, and the other runs distally to anastomose with the third artery. This artery runs in from the caecum along the terminal ileum. It was possible therefore to ligate the main stem of the middle mesenteric artery and the branch which runs proximally from its bifurcation, after ensuring that a sufficient supply of blood for the proximal stump had been left intact, to ligate also the artery coming from the caecum and to remove the lower half of the small intestine; finally it was possible to make an end-to-end anastomosis between the distal end of the jejunum and the terminal $5^{-10} \mathrm{~cm}$ of the ileum. The total length of intestine removed in this way varied from $23^{6}$ to $43^{2} \mathrm{~cm}$, with an average of $320 \mathrm{~cm}$.

Intestinal resection. The operation was performed under general analgesia using ethyl ether administered with an open mask. The abdomen was opened by a mid-line incision from the xiphoid process to the umbilicus. The small intestine was delivered 
entire from the abdomen. There was usually a clear distinction between the jejunum and ileum because the lacteals of the ileum were filled, although this depended to some extent upon when the pig had last been fed. The middle mesenteric vessels were identified in the central part of the mesentery, the peritoneum over them was divided and the vessels were dissected clear and divided between ligatures. The mesentery was then divided between forceps, and the bowel cut across between small crushing clamps. At the distal end of the ileum the marginal vessels running proximally along the small intestine were divided and ligated $5^{-8} \mathrm{~cm}$ from the ileocaecal junction; the intestine was then transected between crushing clamps at the same level. The remainder of the mesentery of the ileum was then divided over clamps and without bleeding, except in three animals (K-M). After excision of the crushed edges of the cut end of the intestine the jejunum and the terminal ileum were anastomosed in one layer, end to end, with interrupted mattress stitches of 0000 silk. In three animals ( $E, F$ and $I)$ the crushed ends of intestine were not cut away before the anastomosis was carried out. $\mathrm{E}$ and $\mathrm{F}$ died on the 2 nd and the $4^{\text {th }}$ day after the operation respectively, with evidence of leakage from the intestine.

After completing the anastomosis the gap in the mesentery was closed by one or two interrupted silk stitches. The wound was closed in two layers with interrupted 2/o silk stitches, one layer in the linea alba and one in the skin. No dressing was applied. Hibitane (ICI) was used to clean the skin before operation, to wipe it over afterwards and to wipe out the ends of the intestine before the anastomosis was made.

Carcass measurements. When the animals were killed, the chest and the abdomen were opened in the mid-line, and the state of the peritoneal cavity and of the intestinal tract within it carefully inspected. The whole of the heart, lungs and guts were then removed en bloc and the adhesions freed; the intestine was dissected out and laid at full length on a bench. After measuring the small and large intestines, the intestinal contents were removed and portions of the small intestine were isolated by ligatures, comfortably filled with formal saline, and removed for histology. Although the whole carcass was thoroughly examined, no abnormalities were found in any of the organs outside the peritoneal cavity.

The carcass measurements were made by the technique described by the National Pig Progeny Testing Board (I959) and Lister \& $\mathrm{McC}$ Cance (1967) and the figures given are the mean values for the two sides of the body.

\section{RESULTS}

One pig died under the anaesthetic from an overdose of ether, one strangled itself I $2 \mathrm{~h}$ after the operation trying to put its head out of its cage, and four died within $48 \mathrm{~h}$ from defects in the anastomosis and from peritonitis. The other ten made a smooth recovery from the operation and, although they suffered from some diarrhoea at first, this always passed off within a few days and subsequently the animals never had loose stools or steatorrhoea. They were fed at first on Amvilac no. I and then on the Amvilac, cereal-fish-meal mixture described by McCance (I960). If they were doing 
well the Amvilac was reduced and then omitted, and finally, as they approached maturity, the animals were given the commercial pig pellets used for the breeding stock. These ten pigs all ate well and gained weight well at first, usually within a week, but two began to refuse food and ceased to put on weight after 2-3 weeks. They both died when they were about 5 weeks old, and at autopsy extensive adhesions were found matting the loops of intestine together in the front of the abdomen. In neither pig was there any evidence of complete obstruction or active peritonitis,

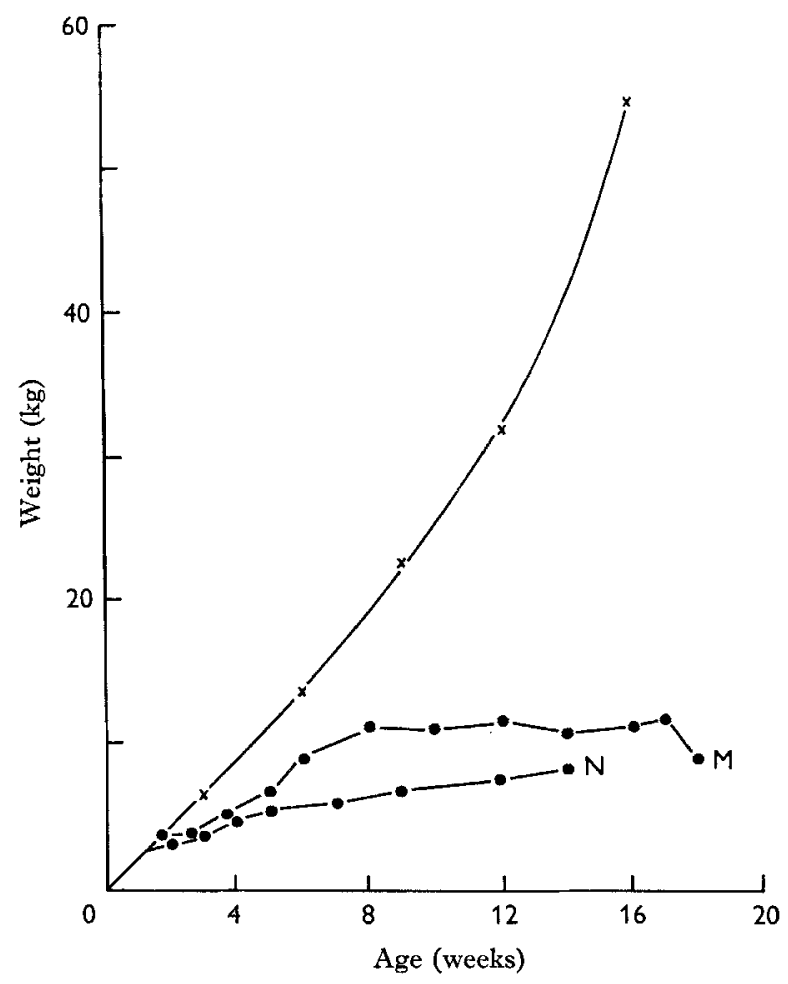

Fig. $r$. Increase in weight of shortgut pigs $\mathrm{M}$ and $\mathrm{N}$ following the operations. The growth curve of a normal pig is also shown. , shortgut pigs; $\times \longrightarrow$, controls.

but there were dilated loops of intestine, suggesting that there had been considerable obstruction, and this was apparently the trouble. $\mathrm{K} \mathrm{L}, \mathrm{M}$ and $\mathrm{N}$ lived for 12-1 8 weeks. $K$ developed a hernia at the site of the incision, and when the $a b-$ domen was reopened to repair this many adhesions were found between the loops of small and large intestine. A number of these were cleared before closing the abdomen. The animal gained weight again for a few days, but died 7 weeks later at the age of $\mathrm{x}_{4}$ weeks at a weight of $6.4 \mathrm{~kg}$.

Fig. I shows the weight charts for $M$ and $N$, known as shortgut pigs $M$ and $N$, from birth to death and the growth curve of a normal litter-mate for comparison. Both $\mathrm{M}$ and $\mathrm{N}$ started to gain after the operation, and it was thought they would do well, but later they began to refuse more and more food in rather a characteristic way. When 
someone went to the pen and took an interest in them they appeared hungry, and at feeding time they often seemed to be ravenous, but after a few mouthfuls they lifted their mouths out of the bowl or began to blow bubbles into the slop and nothing would induce them to take any more. They seldom showed any signs of pain or distress. After death the intestines of all these pigs were found to be matted, and tied down by adhesions.

Pig $\mathrm{H}$ did considerably better than this, lived for 39 weeks (see Fig. 2), and weighed $28 \cdot 2 \mathrm{~kg}$ when it was killed, because of troubles less crippling, but rather like those

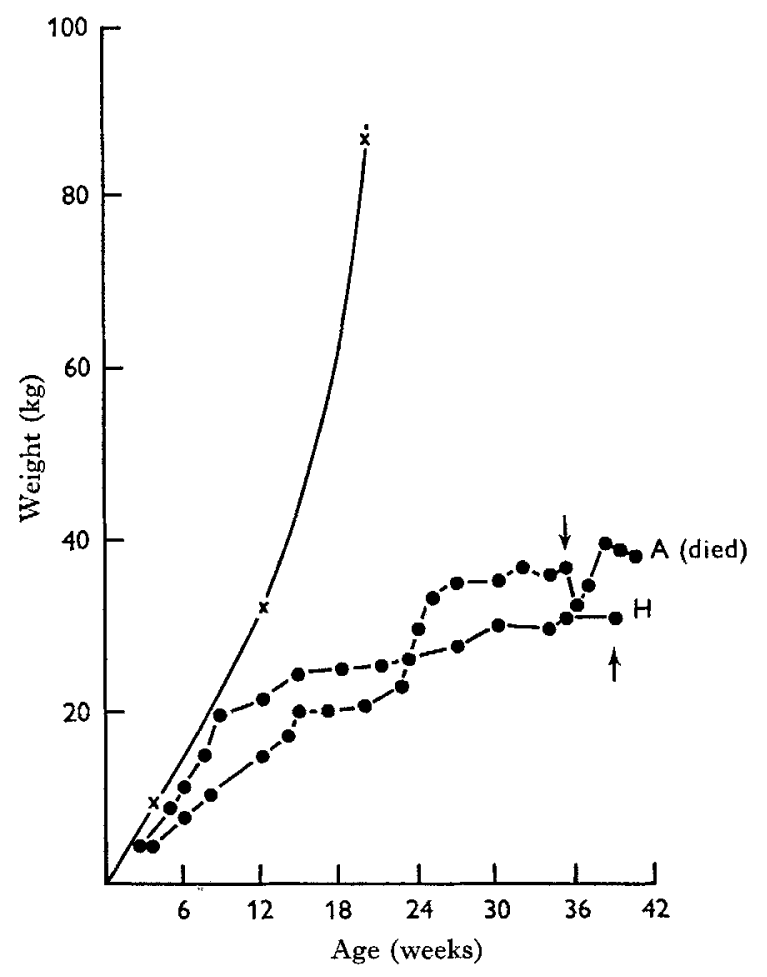

Fig. 2. Increase in weight of shortgut pigs $A$ and $H$ following their operations. The growth curve of a normal pig is also shown. The arrows show the time when the adhesions were freed by the second operation on shortgut $A$, and the time when shortgut $H$ was killed. Notice the difference in the scale of both the ordinate and abscissa from those in Fig. I and Fig. 3.

$\longrightarrow$, shortgut pigs; $\times-\times$, controls.

just described. Pig A, from whom only $235 \mathrm{~cm}$ of intestine had been removed, lived for $4 \mathrm{I}$ weeks, and Fig. 2 shows that it did well for 15 weeks. It gained almost no weight for the next 6 weeks and then suddenly began to do better and gained weight rapidly for 4 weeks, only to reduce eating again and to show signs of considerable distress. It would come to its feeding bowl, but almost at once it began to refuse food, whatever was offered, in the characteristic way, and afterwards it would often stand for long periods with its snout pressed into the corner of the pen. A second operation was carried out, and, in the course of this, many adhesions were found between the small 
and large intestine all over the abdomen. One loop of the small intestine was dilated and partially obstructed. This obstruction was relieved by division of the fibrous contractures and any other adhesions were freed, so far as it was possible to do so, before closing the abdomen. Immediately after the second operation the animal lost weight, but for the next 3 weeks gained weight again rapidly. Later it began to refuse food once more, and finally died. At the autopsy most of the adhesions were found to have reformed, and there was once more one very dilated loop of small intestine and a number of others suggesting widespread minor obstructions.

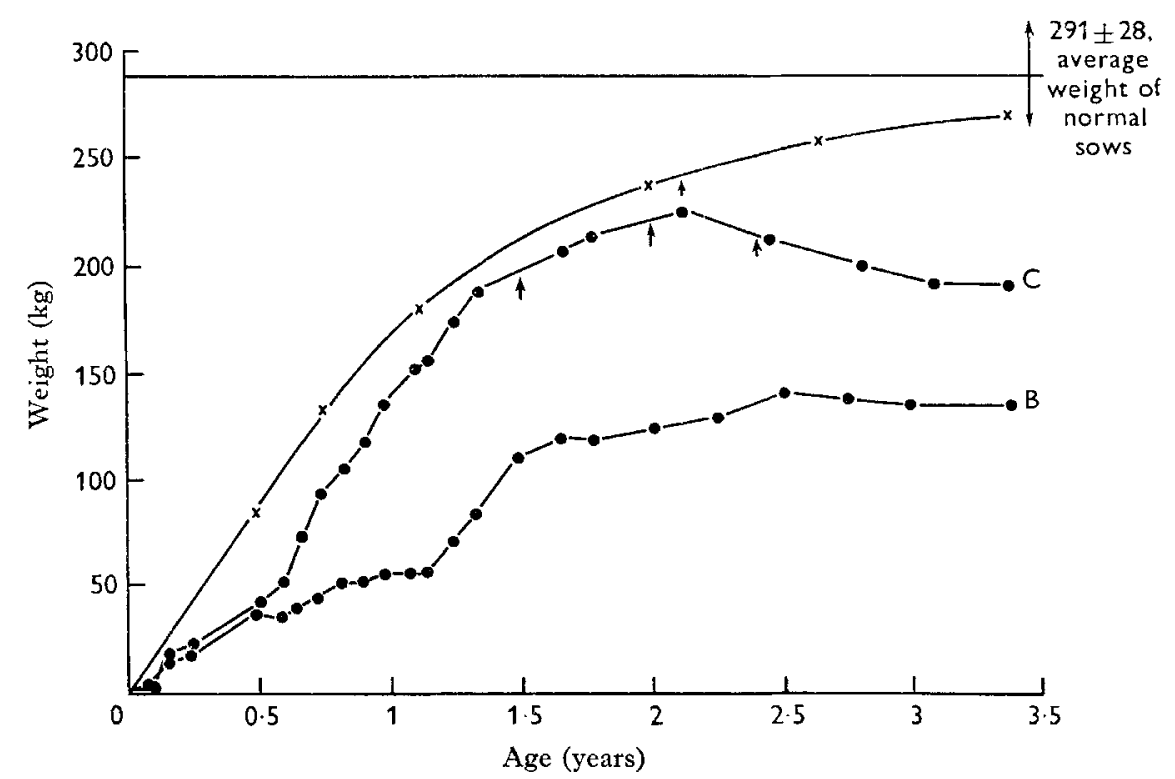

Fig. 3. Increase in weight of shortgut pigs $B$ and $C$. The curve for a normal pig and the average weight and standard deviations of a group of normal sows are also shown. The arrows below the curve of shortgut $\mathrm{C}$ indicate when she had litters; the arrow above the curve shows when her intake of food was reduced.

Pigs B and C did far better than all the others, in spite of resections of 415 and $375 \mathrm{~cm}$ of gut respectively, both well above the average. Their weight curves are given in Fig. 3, together with the growth curve of a normal sow and the final weights of a number of others. After the first few weeks $B$ never did so well as $C$, but she never appeared to be in any pain or distress. For weeks on end, however, she would eat barely enough to maintain her weight constant, and had to be tempted continuously with Amvilac, and occasionally with whole milk. She began to come on heat regularly when she was I 6 months old, and these periods disturbed her enough to produce a loss of weight which she did not make good for about a fortnight. She ate much better on free range in a field inside an electric fence than she did indoors, and was never inside in the latter part of her life. It took her $2 \frac{1}{2}$ years to reach a weight of $\mathrm{I} 44 \mathrm{~kg}$. C grew almost as well as a normal animal, but her pattern of growth was different, and this is well brought out in Fig. 3. She had three litters (marked by arrows on her weight chart), but she was a bad mother, very wild and destructive in and after labour, and 
did not rear any of her second litter. She became very fat in her and year, and her food intake was reduced to that of a normal sow, or a little less. On this she lost weight, and her proportions were about right when she and shortgut $B$ were killed at the age of 3 years and 4 months. Pl. I shows a picture of the pair of them with a normal sow (on the left).

Table I. Carcass measurements for shortgut pigs $B$ and $C$ and the average for three normal adult sows

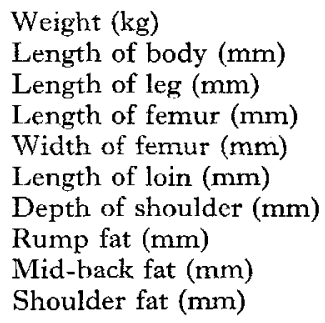

$\begin{array}{ccc}\text { Shortgut B } & \text { Shortgut C } & \text { Adult sows } \\ & & \\ \text { I } 35 & 189 & 270 \\ 991 & 1046 & \text { II } 59 \\ 714 & 687 & 752 \\ 267 & 265 & 281 \\ 32 & 37 & 35 \\ 434 & 504 & 537 \\ 391 & 448 & 564 \\ 8 & 30 & 71 \\ 7 & 19 & 40 \\ 23 & 52 & 71\end{array}$

Table 2. Length of the intestine in normal pigs and in shortgut pigs $B$ and $C$

\begin{tabular}{|c|c|c|c|}
\hline Animal & $\begin{array}{c}\text { Age } \\
\text { (months) }\end{array}$ & $\begin{array}{l}\text { Weight } \\
\text { (kg) }\end{array}$ & $\begin{array}{c}\text { Length of intes- } \\
\text { tine }(\mathrm{cm})\end{array}$ \\
\hline Control: $\frac{1}{2}$ & $\begin{array}{l}4 \\
8\end{array}$ & $\begin{array}{c}45 \\
148+\end{array}$ & $\begin{array}{l}2229^{*} \\
2052^{*}\end{array}$ \\
\hline 3 & 6 & 73 & $2170^{*}$ \\
\hline 4 & 15 & 210 & 18701 \\
\hline Shortgut B & 40 & r35 & 7901 \\
\hline Shortgut C & 40 & 180 & $1020 \ddagger$ \\
\hline
\end{tabular}

Table $\mathrm{I}$ shows the weights and carcass measurements of shortgut pigs $\mathrm{B}$ and $\mathrm{C}$ and also of some normal adult sows. Although $\mathrm{B}$ had always been so thin, and $\mathrm{C}$ had, at one time, been too fat, there was not much difference between their bony measurements and, in fact, B had longer leg measurements than C. B's femur, however, was thinner than that of $\mathrm{C}$, and, unexpectedly, $\mathrm{C}$ had a wider bone than the mean of the normal pigs. The measurements of the soft tissues and fat reflected the state of nutrition of the two animals.

Table 2 shows the weights and the intestinal lengths of four normal pigs and of shortgut pigs $\mathrm{B}$ and $\mathrm{C}$ at death. The measurements on the controls show that the intestines appeared to reach their adult length while the pigs were still comparatively small and young, and those on pigs $B$ and $C$ that the small intestine after death was about half the length to be expected in a normal animal. This is about the fraction of 
the intestine left behind at the operation. There were fibrous adhesions between the loops of intestine, the mesenteries and the abdominal wall in both animals, but they were much more restrictive in $\mathrm{B}$. In this pig there was one thick adhesion binding the lower jejunum to the abdominal wall, and many finer ones, with collections of clear gelatinous material among them binding the lower jejunum to the colon. The wall of the distal jejunum was oedematous from 60 to $210 \mathrm{~cm}$ above the ileocaecal valve and above this level was somewhat dilated when compared with that of a control animal. In $\mathrm{C}$ there were fewer adhesions and no localized dilatation of the intestine above the anastomosis. The jejunum was bound into the form of a $U$, and this was fixed to the abdominal wall, but only the apex of it was in any way distended. The wall of the small intestine appeared to be thicker than that of a normal animal, and its calibre greater. In particular the gross appearance of the jejumun, when laid out on the bench, indicated that there had been some thickening of the wall and dilatation of the jejunum in both $\mathrm{B}$ and $\mathrm{C}$, but it was not possible to make a more quantitative comparison because of the difficulty encountered in inflating the intestines to exactly the same extent. In both animals there were many sites of ectopic bone formation in the mesentery. These deposits of osseous material were embedded in masses of cellular and connective tissue and in some of them there were marrow cavities.

Histological examination of a large number of specimens of intestinal wall taken from just above the anastomoses, just below duodenojejunal flexure and at intervals between these points did not show any distinctive features compared with the corresponding parts of the intestines of normal pigs.

\section{DISCUSSION}

Although many of the pigs failed to grow after these extensive resections, this was satisfactorily accounted for by the adhesions in the peritoneal cavity, and the accompanying abdominal discomfort which produced almost complete anorexia in spite of a normal stomach and pyloric canal. One of the most important positive results, however, which has emerged from these experiments is that a pig can grow almost normally and produce normal litters of young after the removal of most of its ileum; and this, in spite of a limited number of adhesions, including a $U$-bend in the jejunum with some dilatation of the apex. It is clear that pigs, and presumably dogs (Clatworthy et al. I952), must have an enormous reserve of intestinal function.

Clatworthy et al. (1952) found considerable anatomical hypertrophy of the remainder of the intestine after extensive resections in the puppy below the ligament of Treitz, but no increase in length. With the last observation the present results are in agreement. Booth et al. (I959) reviewed the earlier and conflicting work, but they themselves did not find any appreciable anatomical hypertrophy of the upper portions of the small intestine after removal of the lower half in rats. With this also the present work is in agreement, for the varying grades of adhesions and obstruction found were probably enough to account for the localized dilatation and thickening of the intestinal wall. There may have been some increase in the rate and extent of proximal absorption in the remaining proximal part of the intestine, as in the experiments on men re- 
corded by Dowling \& Booth (I966), but if so the 'feedback' mechanism responsible for this will have to be carefully explored.

The adhesions and their consequences were certainly the main reasons for the abdominal discomfort, anorexia and abnormal feeding behaviour of the experimental pigs. This is borne out by the temporary improvement which followed a second operation in pigs $A$ and K. It is also supported by the way in which the anorexia and feeding habits in these pigs resembled the behaviour of some children who have a chronic lowgrade intestinal obstruction with a dilated segment, either secondary to regional ileitis, or following an extensive resection of the small intestine. In such children some temporary improvement may follow a change in the bacterial flora of the intestine, but any lasting improvement usually depends on the relief of the obstruction or the excision of the dilated portion of the intestine. In several children treated by one of us (A.W.W.), division of adhesions was followed by some temporary benefit; a similar benefit was observed in two of the pigs treated in the present experiment.

It has been suggested (Stalgren, Umana, Roy \& Donnelly, I962) that when it is necessary to resect a very large part of the small intestine a short segment at the lower end of what remains should be reversed in order to delay emptying of the proximal intestine and promote more complete digestion and absorption. Observations by one of us (A.W.W.) on infants and young children and the present results on pigs with intestinal stasis suggest that this ingenious procedure may defeat its own object by producing intestinal stasis and so causing a more severe reduction in appetite and food consumption.

There is evidently a future for much more experimental work of this kind. The problem will be to reduce the traumatic effects of the operative procedure, and by doing so to minimize the formation of adhesions. The handling and trauma are certainly the main source of trouble, for three young pigs which were operated upon in exactly the same way, except that the intestines were handled and exposed for a much shorter time and there were no resections, all grew afterwards at a rate which was indistinguishable from normal.

The authors are very grateful to Dr David Lister for his help in the preparation of Table I and to Dr E. M. Widdowson for her advice. The animals were skilfully fed and nursed by Terry Cowen, sometimes at considerable personal sacrifice.

\section{REFERENCES}

Althausen, T. L., Doig, R. K., Uyeyama, K. \& Weiden, S. (1950). Gastroenterology 16, 126.

Booth, C. C., Evans, K. T., Menzies, T. \& Street, D. F. (1959). Br. F. Surg. 46, 403.

Booth, C. C. \& Mollin, D. L. (1959). Lancet i, 18.

Clark, A. C. L. \& Booth, C. C. (1960). Archs Dis. Childh. 35, 595.

Clatworthy, H. W., Saleeby, R. \& Lovingood, C. (1952). Surgery, St Louis 32, 341.

Dowling, R. H. \& Booth, C. C. (1966). Lancet $i$, 146

Flint, J. M. (I912). Bull. Fohns Hopkins Hosp. 23, 125.

Jervis, E. L. \& Levin, R. J (г966). Nature, Lond. 210, 39г.

Lister, D. \& McCance, R. A. (1967). Br. F. Nutr. 21. (In the Press.)

McCance, R. A. (1960). Br. F. Nutr. 14, 59.

National Pig Progeny Testing Board (I959). Rep. natn. Pig Progeny Test. Bd, no. 2, p. I7. 
Pietz, D. G. (1956). Gastroenterology 3I, 56 .

Pilling, G. P. \& Cresson, S. L. (1957). Pediatrics, Springfield 19, 940.

Stalgren, L. H., Umana, G., Roy, R. \& Donnelly, J. (1962). Ann. Surg. 156, 483.

Wilkinson, A. W., Hughes, E. A. \& Toms, D. A. (1963). Br. F. Surg. 50, 225.

\section{EXPLANATION OF PLATE}

Shortgut pigs B (centre) and C (right). There is a normal sow on the left. The weather had been very wet and the normal sow and shortgut $B$ were dirty. Shortgut $C$ could not be contained by an electric fence and had to be kept behind concrete. Hence her clean appearance. 
British Gournal of Nutrition, Vol. 2I, No. 3

Plate I

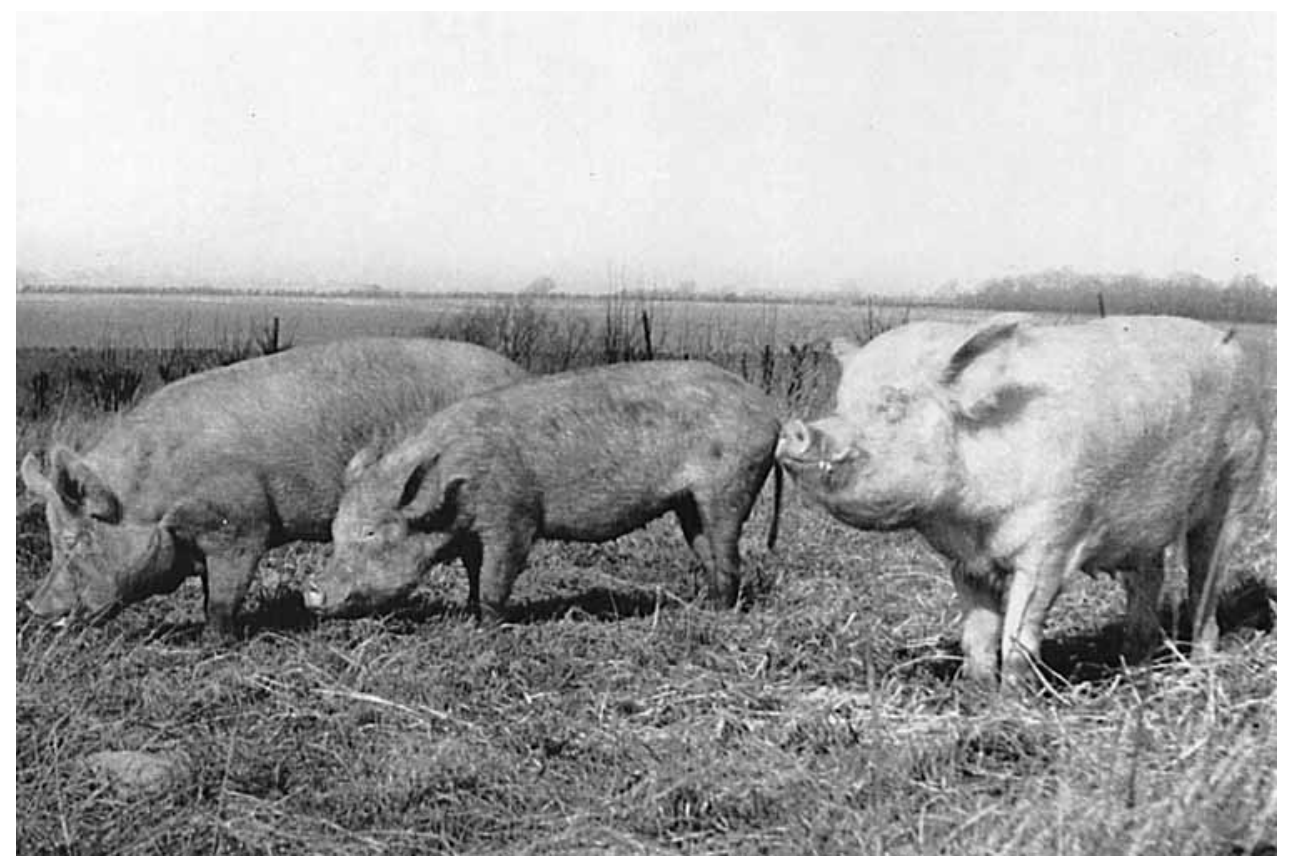

